\title{
Por que silenciadas e invisibilizadas? Relações de gênero nas aulas de matemática
}

Why silenced and no visualized? Gender relation in mathematics classes

\author{
Lindamir Salete Casagrande ${ }^{51}$ \\ Marilia Gomes de Carvalho
}

Artigo recebido em para publicação em out/2012 e aceito para publicação em nov/2012.

\section{Resumo}

O objetivo deste artigo é apresentar resultados parciais de uma pesquisa cujo objetivo foi verificar como acontecem as relações de gênero nas aulas de Matemática de $5^{\underline{a}}$ a $8^{\underline{a}}$ séries do ensino fundamental em um Colégio da rede estadual de educação de Curitiba no Paraná. A pesquisa foi realizada dentro do universo dos estudos sobre gênero e educação. Para a realização da pesquisa utilizou-se o método etnográfico que possibilita a observação dos múltiplos eventos que ocorrem em uma determinada comunidade, no caso, a sala de aula de Matemática. As relações de gênero foram analisadas em quatro turmas da faixa escolar determinada, uma de cada série. O Colégio escolhido para a pesquisa tem mais de cem anos de funcionamento e está localizado na região central de Curitiba. Realizei observações, entrevistas e análise de documentos. Os resultados apontam para relações diferenciadas entre meninos e meninas com a Matemática e entre os/as colegas bem como com o/a professor/a.

Palavras - chave: Relações de gênero. Escola. Alunos e Alunas. Educação. Aulas de Matemática.

\section{Abstract}

The objective of this paper is to present partial results of a study aimed to verify happen as gender relations in mathematics classes from 5th to 8th graders in a statewide network of college education Curitiba in Paraná. This research aimed to analyze gender relations in mathematics classes from 5th to 8th grade of elementary education at a college of Curitiba - Paraná. To

\footnotetext{
${ }^{51}$ Lindamir Salete Casagrande é Doutora em Tecnologia pelo PPGTE/UTFPR; professora do DAMAT/ UTFPR; Pesquisadora do GeTec - Núcleo de estudos de Gênero e Tecnologia. Email: lindasc@utfpr.edu.br.

Marilia Gomes de Carvalho é Doutora em Antropologia Social, professora do PPGTE/ UTFPR; Coordenadora do GeTec. E-mail: mariliagdecarvalho@gmail.com.
} 
conduct the study used the ethnographic method that allows the observation of multiple events occurring in a given community, in this case the mathematics classroom. Gender relations were analyzed in four groups of school age given, one for each series. The College has chosen to search more than one hundred years of operation and is located in the central region of Curitiba. I conducted observations, interviews and document analysis. The results indicate different relationships between boys and girls between the mathematics and, as well as with colleagues the teacher.

Keywords: Gender relations. School. Students. Education. Mathematics Class.

\section{Introdução}

Este artigo tem como objetivo contribuir para a discussão da temática de gênero e educação no meio acadêmico. Para o desenvolvimento da pesquisa ${ }^{i i}$ foi utilizado o método etnográfico que prevê vários procedimentos de coleta de dados, dos quais foram utilizados a entrevista, a observação e a análise de documentos (SARMENTO, 2003). Os resultados aqui apresentados são oriundos da triangulação dos dados obtidos por meio das três formas de coleta/produção de dados.

Foram pesquisadas quatro turmas do ensino fundamental, $5^{\mathrm{a}}$ a $8^{\mathrm{a}}$

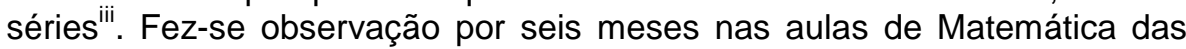
turmas escolhidas. Destas turmas foram selecionados/as quarenta estudantes (vinte de cada sexo e dez de cada turma) para a entrevista. Entrevistou-se ainda os/as professores/as de Matemática (dois homens e duas mulheres) das referidas turmas e fez-se a análise de documentos que continham as notas dos/as alunos/as.

A possibilidade de se conhecer um pouco mais da temática gênero e educação nos levou a pesquisar as aulas de Matemática. Outro fator a influenciar foi a minha formação em Licenciatura em Matemática que me desperta interesse em estudar esta disciplina.

Para a realização desta pesquisa partiu-se do pressuposto de que o gênero é uma das categorias importantes nos estudos sobre a sociedade. A categoria gênero pode ser entendida "como uma linguagem, uma forma de comunicação e ordenação do mundo, que orienta a conduta das pessoas em suas relações específicas, e que é, muitas vezes, base para preconceitos, discriminação e exclusão social" (SIMIÃO, 2005: p. 13). Para Felipe e Guizzo (2003: p. 121), gênero está "relacionado fundamentalmente aos significados que são atribuídos ao ser mulher ou ao ser homem em diferentes sociedades e épocas". Já Scott (1995) considera que as relações de gênero são também relações de poder.

Considera-se que o gênero é social e culturalmente construído. Representa e estabelece relações de poder entre os sujeitos de cada gênero e mesmo entre sujeitos do mesmo gênero (SCOTT, 1995; COSTA, 1994). Assim, todos os segmentos da sociedade contribuem para esta construção, inclusive a escola e os sujeitos que nela atuam. 
Ao adotar a visão relacional de gênero entende-se que "a superação da lógica binária contida na proposta da análise relacional de gênero [...] é fundamental para que se construa um novo olhar aberto às diferenças" (RAGO, 1998, p. 98). Permite a percepção de que as diferenças não significam inferioridades ou superioridades.

Com relação à escola, parte-se do pressuposto de que ela não atua somente como mantenedora da cultura dominante e das regras estabelecidas pela sociedade. Pode ser um instrumento importante na transformação de tais normas para assegurar a todos/as o direito à educação. Desta forma, tem papel importante na construção das identidades de gênero dos/as estudantes, porém não é a única instituição responsável por esta construção. Outras instituições como família e igreja, além da mídia e do convívio em sociedade contribuem de forma significativa para esta construção. Como a pesquisa aqui apresentada foi realizada na escola, o artigo versará sobre o seu papel nesta construção, porém sempre tendo em mente as demais instâncias que constituem os sujeitos.

Com este olhar adentrei a sala de aula e observei o que ocorria lá e uma parcela dos resultados trago neste artigo.

\section{As relações de gênero nas aulas de Matemática}

Conhecer a relação e o posicionamento de meninas e meninos no ambiente escolar é fundamental para poder falar sobre as relações de gênero neste espaço. Foi com este intuito que adentrei a sala de aula para a coleta/produção de dados para a pesquisa aqui apresentada.

A pesquisa foi realizada junto a estudantes e professores/as da rede pública de ensino e se mostrou rica em relações de todo o tipo. Observei as relações de gênero, porém as questões raciais, sociais e relacionadas à sexualidade também se faziam perceber.

Observei que os/as estudantes preferiam se relacionar com colegas do mesmo sexo. Raramente interagiam com colegas do sexo oposto. Este fato diminuía com o passar dos anos. $\mathrm{Na} 7^{\underline{a}}$ e $8^{\underline{a}}$ série havia mais interação entre os/as colegas de sexo diferente, porém, permanecia rara. Este tipo de relacionamento dificultava que os/as estudantes conhecessem as experiências e comportamentos dos/as colegas do outro sexo, conhecimento este fundamental para o dia a dia e deixassem de aprender com o outro. A interação ocorria nos momentos de brincadeiras e de lazer, raramente os/as jovens se reuniam para estudar ou para tirar dúvidas.

No trecho da entrevista com Gervásia citado a seguir percebe-se que ela demonstrava dificuldade no relacionamento com meninos. Esta era a tônica de muitos/as entrevistados/as que evidenciavam tal dificuldade. Sendo a escola um espaço que propicia o convívio entre meninos e meninas, esta dificuldade ou até recusa de relacionamento é um indicativo da construção dos gêneros com papéis diferenciados. Parecia que meninos e meninas viviam em mudos separados mesmo unidos no mesmo espaço físico. 
B: Menina... eu quase nem tenho... nem converso muito com os piáv ... as vezes eles pedem... a única coisa que eu falo ... as vezes eles pedem dá uma bala... só ... agora mesmo eu conversei com o Adriano sobre o trabalho... só assim.

A: Mas por quê você acha que tem mais meninas?

B: Por que ... ai:.:. eh que é estranho falar com meninos... ah eu não me dou bem... eu acho estranho... eu não gosto muito... prefiro mesmo menina... (Gervásia, 6aㅗ série)

$\mathrm{Na} 8^{\mathrm{a}}$ série observei um fato que pode justificar a pouca relação entre colegas de sexo distinto para o estudo. O comentário do professor constante no excerto a seguir sobre o fato do menino se unir com a menina para resolução dos exercícios causou constrangimento em ambos e no restante das aulas que observei, eles não aproximaram mais as carteiras para estudar, continuavam conversando, mas cada um tentava resolver os exercícios em sua carteira. Percebeu-se que a postura dos/as professores é um dos fatores que dificulta a interação entre estudantes de diferentes sexos.

*Você vai juntar com a Eliane, quem sabe já rola um romance. ${ }^{*}$ A turma ri, a aluna fica vermelha e o aluno derruba o penal ${ }^{\mathrm{vi}}$. (DC vii, $8^{\text {a }}$ série $24 / 09 / 2009$ )

Os motivos para a preferência pela relação entre estudantes do mesmo sexo eram os mais variados. Nos trechos de entrevista a seguir é possível perceber alguns destes motivos.

A: por que você se relaciona melhor com elas?

$\mathrm{B}$ : porque eu acho que como menina... as meninas me entendem melhor:::

A: você acha que os assuntos dos piá e das meninas são diferentes?

B: são diferentes... alguns são iguais mas a maioria são diferentes (Vitória, da $5^{\mathrm{a}}$ série)

A: no teu grupo de amigos tem mais meninos ou meninas?

B: meninos

A: por que você acha que isso acontece?

$\mathrm{B}$ : ah pelo fato de eu ser menino né ... porque sei lá... menino gosta de ... futebol ::: de computador ... disso daí né e daí menina já gosta de outro tipo de coisa ...dai o assunto não é o mesmo. (Francisco, $6^{a}$ série)

Esta preferência era baseada em estereótipos sobre o que é ser homem ou ser mulher. Demonstra que eles/as estão impregnados da forma dicotômica de viver a masculinidade e a feminilidade. Indica que desde muito cedo os/as jovens têm suas identidades de gênero construídas com base em papéis sociais atribuídos a um e a outra. Essa construção é feita por meio das múltiplas instituições que interferem na formação dos/as jovens. Evidencia ainda que a socialização diferenciada de meninos e meninas se faz notar na fala de Francisco. É possível deduzir que, na opinião dele, meninas não gostam de futebol e computador, e, por outro lado, os meninos não podem se interessar pelos assuntos que as meninas gostam de comentar. 
O fato dos meninos terem interesses por assuntos semelhantes, o mesmo ocorrendo com as meninas, seria um dos fatores que contribuiria para que elas e eles se unissem no clubinho do "bolinha" e da "luluzinha"viii. Nestes "clubes"não se permite o ingresso de jovens de outro sexo. Ao se unirem nestes grupos não se propicia a relação entre estudantes de sexos distintos. A necessidade de pertencimento ao grupo pode inibir os/as jovens que gostariam de quebrar esta fronteira.

Os/as estudantes percebiam que existia diferença na forma como alunos e alunas se relacionavam entre si e com a Matemática. Elas eram vistas como mais caprichosas, dedicadas e obedientes e eles como mais questionadores e ativos. Esta ideia perpassava a fala de meninos e meninas e evidenciava a perpetuação dos estereótipos construídos socialmente como características masculinas e femininas. Os/as estudantes não percebiam essas questões como construídas e sim "naturalizadas". Se forem construídas podem ser modificadas, uma vez "naturalizadas" não é possível modificar, há que se conformar com a natureza. Nos dias atuais não é possível aceitar situações discriminatórias como naturais. O questionamento é fundamental para a busca de igualdades.

Outro fenômeno a se observar é que os/as estudantes se percebem de forma diferenciada no que diz respeito ao comportamento. Nos trechos citados a seguir pode-se perceber tal diferença na percepção dos/as estudantes. A "bagunça" é vista como um comportamento mais predominante nos meninos. Porém nas observações pude perceber que elas encontravam formas de se divertir durante as aulas, de forma mais discreta e silenciosa do que eles, porém tão frequente quanto. Ou seja, as "bagunças" eram diferentes, porém existia tanto entre os meninos quanto entre as meninas. A maioria dos/as entrevistados reconhecia na desordem um fator que atrapalhava o rendimento escolar, como relata Gervásia no excerto a seguir. Fernanda ressalta que o fato delas falarem mais alto dava a sensação de que elas eram mais bagunceiras, porém nesta classe os papéis se invertiam e os meninos eram mais discretos e silenciosos. A $7^{a}$ série era uma turma diferenciada. Nela as meninas eram mais participativas, barulhentas, desordeiras e obtinham as melhores notas diferentemente das outras turmas nas quais as meninas eram menos participativas e mais discretas.

A: Quem é mais bagunceiro os piás ou as meninas?

B: Oh... os piás fazem bastante bagunça mas é que a gente fala mais alto então dá a impressão de que a gente faz mais bagunça mas é que por exemplo os meninos tão lá no grupinho deles e tem só duas meninas ali as meninas falam mais alto que eles entendeu só que eles fazem mais bagunça entendeu as vezes eles ficam gritando assim soltam uma gargalhada sei lá. (Fernanda, $7^{\mathrm{a}}$ série)
A: O que interfere no teu rendimento?
B: Bagunça... interfere bastante.
A: Bagunça dos colegas ou quando você conversa?
$\mathrm{B}$ : Eu não converso tanto pra ser bem sincera... quando a professora tá explicando quando eles fazem pergunta ... ai é isso é aquilo... as vezes elas me chamam eu falo ah deixa eu prestar 
atenção que ela tá explicando coisa assim... mas eu acho que a bagunça mesmo dos meninos ... interfere bastante.

A: Quem é mais bagunceiro?

B: Os meninos... com certeza os meninos. (Gervásia, 6ª série)

As meninas estão mais concentradas do que os meninos. Eles pedem mais auxílio da professora. [Isso pode significar que elas sabem mais a matéria, mas pode significar também que têm mais receio de recorrer à professora para esclarecer dúvidas. Pode significar menos interesse delas em tirar boas notas. Ou significar ainda que eles estão utilizando de todas as armas para se darem bem e elas não.] (DC, 6ª série, 15/04/2009)

De modo geral, os/as estudantes percebiam os meninos como mais desordeiros, porém não negavam que as meninas também faziam parte da desordem, mas de forma diferenciada. Esta diferença de postura de alunos e alunas era percebida pelos/as professores/as e entendida como normal do comportamento masculino e feminino. Ao enxergar como normal, ações que poderiam minimizar esta questão não eram tomadas e atos que poderiam se converter em discriminação e preconceito continuavam a ocorrer no ambiente escolar. A visão de professores/as e estudantes era baseada nos estereótipos de homens e mulheres. Estes estereótipos eram social e culturalmente construídos por meio da socialização diferenciada que ocorre desde a mais tenra idade, porém professores/as e estudantes não possuíam esta percepção.

O fato das meninas pedirem menos auxílio às/aos professoras/es pode indicar que elas foram silenciadas. Desde muito cedo aprendem que devem ouvir mais do que falar. Ficou evidente que as professoras da $5^{\mathrm{a}}$ e $6^{\mathrm{a}}$ séries davam mais atenção aos meninos, fato que estimulava a maior participação deles e o silenciamento delas. Este silenciamento gerava dificuldade de expor suas fraquezas e dúvidas e dificultava o aprendizado delas.

Percebeu-se que os/as estudantes utilizavam-se de estratégias diferentes para atingir suas ambições que eram muito próximas. Embora diferentes todas as estratégicas se mostravam eficientes e os/as ajudavam. As estratégias eram vinculadas às características percebidas como naturais de cada gênero. Ou seja, os/as estudantes se adaptavam às possibilidades de cada um/a. Da mesma forma que a postura dos/as jovens dependia dos estereótipos, as estratégias encontradas pelos/as estudantes eram baseadas em tais estereótipos.

A: Quem desobedece mais?

B: Acho que os meninos.

A: Por que você acha que isso acontece?

B: Porque assim ... na verdade são os dois ... só que as meninas elas são mais reservadas assim ... elas são mais ... mais no grupinho... elas se fecham no grupinho e os garotos não... eles são mais... são mais extravagantes ... são mais ...eles falam pra turma inteira então eles acabam atrapalhando um pouco mais. (Pedro, $8^{\mathrm{a}}$ série) 
O professor entrega as provas. Duas meninas tentam se comunicar. Uma aluna usa a calculadora do celular. Ouço o barulho das teclas. (DC, 8ª série, 09/06/2009)

Romper as regras é uma forma de fazer valer suas vontades e demonstrar que não existe uma submissão completa ao que é determinado pelo/a professor/a. É uma forma de se apropriar do poder e fazê-lo circular, no conceito de Foucault (2009). Os meninos eram mais barulhentos ao romper as regras e as meninas mais sutis, porém todos/as infringiam-nas. Aparentemente o comportamento de uns e outras era resultado da forma como foram socializados/as bem como das expectativas que a sociedade tem de cada um/a.

Da mesma forma que os/as estudantes, os/as professores/as percebiam as meninas e meninos com comportamentos diferenciados. Elas eram vistas como mais caprichosas, dedicadas e esforçadas e ele como mais desleixados, ativos e participativos. São percepções baseadas nos estereótipos que prevêem as mulheres e os homens com tais características. Embora houvesse este comportamento diferenciado, não era possível perceber reflexo do mesmo nos rendimentos dos/as estudantes.

As relações de gênero eram silenciadas, não percebidas por professores/as e estudantes. Louro (2001) argumenta que tão importante quanto escutar o que é dito é perceber o que é silenciado. Por que há este silenciamento? Esta é uma pergunta importante a ser feita quando se depara com uma situação destas. Nesta pesquisa pode-se perceber que os/as profissionais não percebiam as relações de gênero como fator que influenciava no processo ensino/aprendizagem. Porém o silenciamento das meninas era um componente que influenciava no desempenho delas. Elas se calavam diante das dúvidas. Tentar entender os motivos que levam ao silenciamento é fundamental para as discussões de gênero e para a melhora do processo de ensino/aprendizagem.

A vergonha foi apontada como causa para que os estudantes silenciassem no que diz respeito às dúvidas durante as aulas. Os/as estudantes tinham vergonha de perguntar, com receio da reação dos/as colegas. Esta atitude se reflete diretamente no desempenho escolar dos/as estudantes e pode fazer com que estes deixem de tirar suas dúvidas sobre o conteúdo. Assim, o acúmulo das dúvidas se reflete em baixo desempenho escolar. Aponta ainda a necessidade de pertencimento ao grupo por parte dos/as estudantes. Eles/as precisam ser conhecidos/as e reconhecidos/as pelos/as colegas como um/a deles/as e por isso silenciam com receio de que, ao expor suas ideias, possam ser vistos como diferentes como não pertencentes àquele grupo. Se a ideia fosse correta seriam chamados de "CDF" "ix se fosse equivocada seriam rotulados de "burros". Ambas as situações não eram desejadas pelos/as estudantes, então, calavam-se. Os/as professores/as não percebiam este silenciamento e não tomavam providências para melhorar a participação dos/as estudantes.

Os/as estudantes percebiam tais situações. Isso fica perceptível nos trechos de entrevista a seguir. 
A: Em algum momento você percebeu que alguém fez um pergunta e o outro tirou sarro ... acontece isso?

B: Acontece...também ontem... o Ivo as veis ele fais pergunta... ele :.:: a professora ... todo mundo já tá sabendo... coisa facinha... coisa nada a vê assim ele pega e pergunta ... mas professora esse daqui é diferente desse número que igual a esse daqui... bem nada a vê as perguntas daí eu tira... daí os piá tira sarro daí. (Braulin, 5ª série)
A: E como você acha que as pessoas que perguntaram se sentem quando alguém tira sarro delas?
B: Elas se sentem magoadas.
A: Já tiraram sarro de alguma pergunta que você fez?
B: Eu não faço pergunta então não tem... eu não faço pergunta.
(Bianca, $5^{\mathrm{a}}$ série)

Percebeu-se uma recusa em assumir a participação dos/as entrevistados/as nas ações vexatórias. Esse fato fica perceptível na fala de Braulin, aluno da $5^{\mathrm{a}}$ série. Ele começa a dizer que ele faz, mas, em seguida se corrige e diz que todos os meninos tiram sarro dos colegas. Por outro lado, a fala de Bianca evidencia o silenciamento que pode indicar o receio de ser vítima de chacotas. Sem dúvida a vergonha e o receio de serem vitimadas fazem com que as relações em sala de aula se modifiquem e tornem-se menos ricas. Esta vergonha influencia na aprendizagem e dificulta a elucidação das dúvidas, o que se traduz em baixo rendimento tanto de meninos quanto de meninas.

Durante a pesquisa pude perceber que os/as estudantes mais participativos/as eram também os que obtinham as melhores notas. Porém não foi possível concluir se eles perguntavam mais por terem mais conhecimento o que os deixaria seguros para se expor ou se tinham melhores rendimentos por que perguntavam mais e elucidavam suas dúvidas, talvez seja as duas coisas.

O comportamento dos/as colegas com relação às dúvidas dos demais interferia na postura dos estudantes durante as aulas de Matemática e poderia contribuir para o baixo rendimento dos mesmos, fato observado nas análises dos diários de classe (CASAGRANDE; CARVALHO, 2011). Esta postura dos/as colegas interfere mais no comportamento das meninas do que dos meninos.

\begin{tabular}{|c|c|c|c|c|}
\hline \multirow{2}{*}{ Séries } & \multicolumn{3}{|c|}{ Médias anuais - 2009} & \multirow{2}{*}{$\begin{array}{c}\text { Diferença entre as médias das alunas e } \\
\text { dos alunos } \\
\left(D=2^{\text {a }} \text { coluna }-3^{a} \text { coluna }\right)\end{array}$} \\
\hline & Alunas & Alunos & Geral & \\
\hline $5^{\mathrm{a}}$ & 61,5 & 59,4 & 60,3 & 2,1 \\
\hline $6^{a}$ & 51 & 54,1 & 52,6 & $-3,1$ \\
\hline $7^{\mathrm{a}}$ & 60,9 & 58,3 & 59,8 & 2,6 \\
\hline $8^{\mathbf{a}}$ & 57,4 & 60,7 & 59 & $-3,3$ \\
\hline Total & 57,8 & 58,2 & 58 & $-0,4$ \\
\hline
\end{tabular}

Fonte: tese "Entre silenciamentos e invisibilidades: relações de gênero no cotidiano das aulas de matemática" 
No que diz respeito às notas obtidas pelos/as estudantes, em sua maioria eram baixas (Quadro 01), ficando as médias das turmas muito próximas ao mínimo necessário para a aprovação que no estado do Paraná é 6 (seis), porém todas as médias eram baixas.

A iniciativa dos meninos de perguntar mais e o comportamento disciplinado das meninas não resultava em boas notas (CASAGRANDE; CARVALHO, 2011). Embora existisse diferença entre o rendimento dos alunos e das alunas, não foi possível concluir que esta diferença levava à superação de um sexo sobre outro, pois em duas turmas a vantagem favorecia às alunas e nas outras duas, aos alunos. Porém, na percepção dos/as estudantes o melhor rendimento era das alunas (Quadro 02). Talvez pelo fato de que elas eram percebidas como mais dedicadas, organizadas e estudiosas, os/as estudantes acreditavam que o rendimento delas era melhor e que resultaria em melhores notas, fato que não necessariamente acontecia. Ser percebidas como mais caprichosas e dedicadas levava-os a pensar que elas tivessem melhor rendimento do que eles. Ou seja, é uma imagem baseada nos estereótipos.

\begin{tabular}{|c|c|c|c|c|c|c|}
\hline \multirow{2}{*}{ Série } & \multicolumn{3}{|c|}{$\begin{array}{c}\text { Percepção dos alunos sobre } \\
\text { quem obtém melhores notas }\end{array}$} & \multicolumn{3}{c|}{$\begin{array}{c}\text { Percepção das alunas sobre } \\
\text { quem obtém melhores notas }\end{array}$} \\
\cline { 2 - 7 } & meninos & meninas & independe & meninos & meninas & independe \\
\hline $\mathbf{5}^{\mathbf{a}}$ & 1 & 3 & 1 & 3 & 2 & 0 \\
\hline $6^{\mathbf{a}}$ & 4 & 0 & 1 & 5 & 0 & 0 \\
\hline $7^{\mathbf{a}}$ & 0 & 3 & 2 & 0 & 3 & 2 \\
\hline $\mathbf{8}^{\mathbf{a}}$ & 0 & 4 & 1 & 1 & 2 & 2 \\
\hline total & 5 & 10 & 5 & 9 & 7 & 4 \\
\hline
\end{tabular}

Quadro 02- Percepção dos/as discentes sobre o rendimento de alunas e alunos

Fonte: tese "Entre silenciamentos e invisibilidades: relações de gênero no cotidiano das aulas de matemática"

Ao serem questionados/as sobre as expectativas profissionais a maioria dos/as jovens afirmou que pretendia cursar nível superior. Seis estudantes (15\%) gostariam de cursar as engenharias (quatro alunos e duas alunas) e sete (17,5\%) seguir carreiras relacionadas à área da saúde (três alunos e quatro alunas). Este fato indica que os/as jovens da escola pública almejavam seguir carreiras valorizadas financeira e socialmente. Este é um indício de que a escola pública está oferecendo condições para que os/as jovens almejem estudos superiores nas mais variadas áreas. Estimular os/as estudantes a prosseguir sua vida escolar é um dos papéis da escola, que, aparentemente está sendo cumprindo.

Não foi possível estabelecer uma relação direta entre o rendimento em Matemática e as expectativas profissionais, porém os/as estudantes que almejavam as engenharias e as carreiras da área médica obtiveram bom rendimento em Matemática no ano pesquisado (2009). Por meio deste indicativo podemos dizer que o bom desempenho em Matemática contribui para a expectativa profissional. Falamos em expectativa, pois ainda era muito cedo para que os/as jovens fizessem suas escolhas profissionais. São 
jovens de 10 a 16 anos e somente ao final do ensino médio deverão fazer escolhas de cursos superiores que indicarão suas tendências profissionais.

Mesmo que o rendimento escolar em Matemática não seja um indicativo claro, pode-se dizer que é um dos fatores que influenciam nas expectativas profissionais. Quando se observa que somente alunos com notas acima da média na referida disciplina têm interesse em carreiras científicas e tecnológicas pode-se fazer esta inferição. Existe uma valorização diferenciada das carreiras e as voltadas para as ciências e tecnologias são mais valorizadas e os meninos afirmaram mais frequentemente desejar tais carreiras. Estas expectativas são um reflexo da sociedade atual na qual as mulheres são minoria nos cursos de engenharia, porém a pesquisa apontou que $1 / 3$ dos estudantes que pretendiam seguir esta carreira eram meninas.

Ainda sobre a relação dos/as estudantes com a Matemática, a maioria afirmou gostar da disciplina, porém seus rendimentos eram vistos por ele/as como médios. Outros diziam que o rendimento era baixo, mas mesmo assim gostavam da Matemática. Este resultado contraria a ideia corrente de que os/as estudantes não gostam de Matemática.

De modo geral, as questões de gênero se mostraram imperceptíveis para estudantes e professores/as como fator que influenciava no rendimento escolar de alunos e alunas. Este silenciamento sobre as relações de gênero indicava a naturalização destas questões no ambiente escolar. Tão naturais que se tornavam quase imperceptíveis e silenciadas por todos/as os/as participantes da pesquisa. Não perceber como as relações de gênero influenciam na relação de meninos e meninas com a Matemática é desperdiçar oportunidades de enriquecimento do processo ensino/aprendizagem. É deixar de proporcionar melhores condições de aprendizagem a todos/as.

Os/as estudantes e professores/as manifestaram ter absorvido as normas impostas pela socialização diferenciada de meninos e meninas, nas quais elas são ensinadas a cuidar, a preservar seus brinquedos e objetos pessoais, viver no espaço doméstico e eles a experimentar, desmontar e montar novamente seus carrinhos e brinquedos, viver no espaço público. A socialização ensina mulheres a silenciar a não se expor e não expor suas ideias e isso se reflete na escola onde as meninas silenciam diante das diversas situações. Esta socialização diferenciada que ocorre de várias formas contribui para que homens e mulheres construam e manifestem de forma diferente suas expectativas de vida e profissionais.

\section{Considerações finais}

Ao concluir a pesquisa pudemos observar que o caminho para a busca da equidade ainda é longo, porém alguns passos têm sido dados. Passos esses fundamentais nesta caminhada.

No ambiente escolar, embora existam muitas diferenças entre o comportamento de meninas e meninos, em alguns momentos existe a interação. São comportamentos diferenciados porém não podem ser lidos 
como desiguais. $O$ fato de uns serem mais expansivos e comunicativos que outros não os torna melhores ou piores. Estudantes de gêneros distintos se comunicam entre si nos momentos de lazer, mas raramente em momentos de estudos. É importante salientar que a busca do estudo em conjunto, do apoio dos colegas na resolução dos problemas e exercícios ocorria muito raramente, ou seja, nem mesmo entre estudantes do mesmo sexo havia esta troca de conhecimento. Este comportamento era mais frequente entre as meninas.

Os gêneros agem de forma diferenciada e buscam formas distintas de alcançar seus objetivos. Meninas e meninos encontram formas diferentes de assegurar suas ambições, seus desejos. Ressalto que as ações eram distintas porém não menos eficazes. As relações de gênero são repletas de poder que perpassam as relações do cotidiano e se manifestam em sala de aula. Os/as estudantes encontravam maneiras eficientes de manifestar seu poder, de fazê-lo transitar, circular no espaço da sala de aula.

Os gêneros são fatores que estão presentes no cotidiano escolar e raramente são percebidos pelos sujeitos que nele atuam. Por esse fato são negligenciados e silenciados por todos/as. Tanto as relações de gênero quanto as meninas são silenciadas e se silenciam diante das situações do cotidiano escolar. As meninas são silenciadas ao não serem percebidas nem ouvidas pelos professores/as e ao serem descritas como mais obedientes pelos discentes.

Embora não se concorde com a concepção de gênero como papéis dicotomizados, o que se observou na pesquisa é que meninos meninas se percebiam como pertencentes a mundos diferentes, com interesses e desejos distintos. Como se eles e elas tivessem que assumir papéis específicos destinados a cada um e que um não podia transitar no universo do outro.

Percebeu-se que os/as professores/as não encontram-se preparados para minimizar as desigualdades de gênero em sala de aula e propiciar uma educação igualitária. Há a necessidade de se preparar os/as professores/as para tratar as questões de gênero que ora são quase imperceptíveis aos seus olhos.

\footnotetext{
'A pesquisa que deu origem a este artigo foi realizada durante o período de 2008 a 2011 para a realização de uma tese de doutorado desenvolvida junto ao Programa de Pós-Graduação em Tecnologia - PPGTE da Universidade Tecnológica Federal do Paraná - UTFPR. A tese foi defendida em dezembro de 2011.

ii Esta era a nomenclatura utilizada na época da pesquisa e equivale ao 6 o ao 9 o ano na atualidade.

iii"A letra "A" indica a fala da entrevistadora e "B" a fala do/a entrevistado/a.

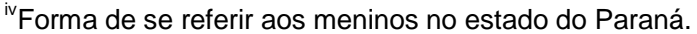

${ }^{\vee}$ Forma curitibana de se referir ao estojo para lápis e canetas.

víDiário de campo será doravante denominado de DC.

viiiTermos utilizados pelos jovens para designar grupos de meninos e de meninas.

viii Na gíria dos estudantes CDF significa pejorativamente cabeça de ferro, alunos que estudam bastante e tiram boas notas.
} 


\section{Referências}

CASAGRANDE, Lindamir Salete; CARVALHO M. G., Marilia Gomes (2011). Desempenho escolar em Matemática: o que o gênero tem a ver com isso? In: CASAGRANDE, Lindamir Salete; LUZ, Nanci Stancki da., CARVALHO, Marilia Gomes de. (Orgs) Igualdade na Diversidade: enfrentando 0 sexismo e a homofobia. Curitiba: Editora da UTFPR, p. 269-306.

CASAGRANDE, Lindamir. Salete. Entre silenciamentos e invisibilidades: as relações de gênero no cotidiano das aulas de matemática. 2011, $261 \mathrm{f}$. Tese (Doutorado em Tecnologia), Programa de Pós-Graduação em Tecnologia, Universidade Tecnológica Federal do Paraná, Curitiba, 2011. COSTA, Claudia de Lima. (1994) O leito do procusto. Cadernos Pagu, Campinas, p. 141-174.

FELIPE, Jane; GUIZZO, Bianca Salazar. (2003). Erotização dos corpos infantis na sociedade de consumo. Pro-Posições, Campinas, v. 14, n. 3 (42), p. 121-130.

FOUCAULT, Michel (2009). Microfísica do poder. 27. reimp. Rio de Janeiro: Edições Graal.

LOURO, Guacira Lopes (2001). Gênero, sexualidade e educação: uma perspectiva pós-estruturalista. Petrópolis: Vozes.

RAGO, Margareth (1998). Descobrindo historicamente o gênero. Cadernos Pagu, Campinas, 11, p. 89-98.

SARMENTO, Manuel J (2003). O estudo de caso etnográfico em Educação. In: ZAGO, N; CARVALHO, M. P.; VILELA, R. A. T. (Orgs.). Itinerários de Pesquisa. Rio de Janeiro: DP\&A, p. 109-136.

SCOTT, Joan. (1995) Gênero: Uma categoria útil de análise histórica. Educação \& Realidade, Porto Alegre, v. 20, n. 2, p. 71-99.

SIMIÃO, Daniel Schroeter (2005). Gênero no mundo do trabalho: variações sobre um tema. Cadernos de Gênero e Tecnologia, v. 5, ano 2, p. 9-20. 